\title{
Nineteenth-century cast-iron parapet of Blackfriars Road Bridge, London, UK
}

Deborah Lazarus MA(Cantab), CEng, FICE, FIStructE, FRSA

Consultant, Arup AT\&R, London, UK (deborah.lazarus@arup.com)

Blackfriars Road Bridge in London, UK, is a Grade II-listed structure dating from 1869 and widened at the start of the twentieth century. In the 1960s, a concrete staircase was constructed linking the east side of the bridge to the riverside park below. The Blackfriars Millennium Pier reconstruction project is being carried out as part of the work associated with the new Thames Tideway Tunnel 'supersewer', designed to tackle sewage overflows into the River Thames. It includes removal of the 1960s staircase and its replacement with a new staircase and lift to improve access between the riverside walkway and the bridge. Alterations, which required listed building consent, were needed to the bridge's ornate cast-iron parapet, namely infilling of the opening created for the 1960s stair and creation of a new opening to accommodate the new access. This paper discusses what was known about the original parapet construction, what was found during the course of the works and the approach that was taken to minimise loss of the original ironwork. It looks briefly at the issue of design loading on the parapet and the works undertaken on the cast-iron parapets of two other bridges of similar age.

\section{Introduction}

Blackfriars Road Bridge spans the River Thames to the east of Waterloo Bridge and just west of Blackfriars Rail Bridge and station in London, UK. Victoria Embankment lies to the north, and to the south is the bankside area. The Blackfriars Millennium Pier reconstruction project is being carried out as part of the work associated with the new Thames Tideway Tunnel 'supersewer', designed to tackle sewage overflows into the River Thames.

Improvements in access from the riverside walkway to the road bridge have included reconfiguration of stair access on the east side, with resulting alterations to the bridge's ornate cast-iron parapet. The bridge, which is owned by the City of London Corporation as trustees of the Bridge House Estates, is listed, and these works have required careful consideration of changes to the historic fabric. Listed building consent was required for the works, necessitating provision of detailed proposals. Throughout the works, there has been close liaison with Historic England and the City of London. While some original drawings of the parapet were located, details found on-site were not fully consistent with the records. In addition, the condition of some components of the parapet was found to be significantly worse than what had been anticipated from visual inspection. This required more extensive replacement of original cast-iron elements than had been assumed at the outset. It also raised issues regarding the condition of the structure along the bridge more generally and its ability to withstand impact loads from the heavy vehicles which routinely use the bridge. Current traffic loads are very different from those at the time of the original construction, and requirements concerning accidental impact loads have also become more stringent. The approach adopted for the new elements is described.

This paper describes the original construction, the investigations carried out and the final details adopted. It also looks at the testing of the parapet carried out by the City of London. It should be noted in this regard that the bridge is inspected and maintained using private funds from the Bridge House Estates, at no cost to the public.

In addition to looking at the works at Blackfriars Road Bridge, the paper refers more briefly to works undertaken recently at two other bridges of similar age and construction. It considers the different approaches adopted and the reasons behind these, together with the implications for other historic structures and potential solutions for structural safety. The balance between risk mitigation and the desire to maximise the retention of historic fabric is addressed.

\section{Background to the works}

The works associated with the Millennium Pier reconstruction project include (Thames Tideway Tunnel, 2015)

- removal of the 1960s staircase access between the 1960s riverside walkway and the east footway of Blackfriars Road Bridge

- restoration of the staircase opening in the cast-iron parapet which was formed to accommodate the staircase to its pre1960s configuration

- creation of a new opening in the parapet slightly to the north of that formed in the $1960 \mathrm{~s}$

- construction of a new staircase (and also a lift), with a less visually intrusive connection with the bridge than the existing staircase.

Subsequently, the replacement of severely corroded cast-iron elements within the overall zone of the works was also incorporated. The works result in minor alterations to the fabric of the bridge's east parapet, but they improve the visibility of the bridge's north span from the south-east, when compared with the previous arrangement. They are also intended to enhance the 
Engineering History and Heritage

Volume 171 Issue EH4
Nineteenth-century cast-iron parapet of Blackfriars Road Bridge, London, UK

Lazarus

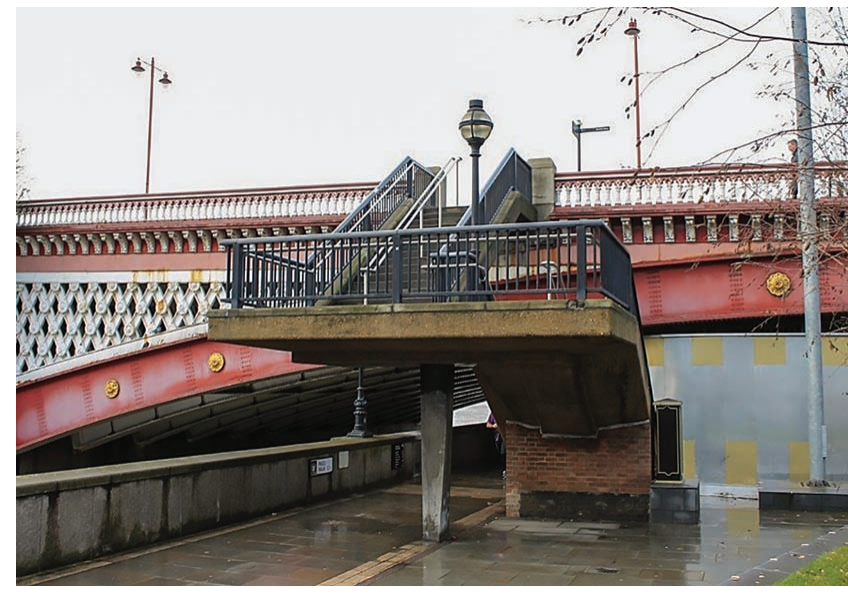

Figure 1. The 1960 s staircase seen from the embankment, showing infilling and obscuring of the northern bridge span

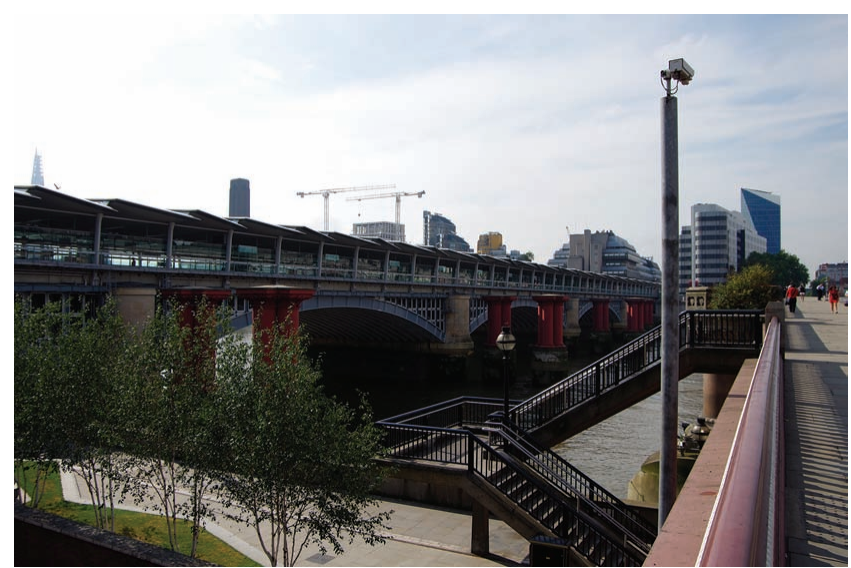

Figure 2. The 1960s staircase viewed from the eastern footway of Blackfriars Road Bridge

character and appearance of Whitefriars Conservation Area and preserve the significance of the listed bridge.

The existing staircase, which might be described as somewhat utilitarian in design, intruded in the settings of both the bridge (see Figure 1) and the conservation area. It obscured views of the northern bridge span when seen from the platforms of the Blackfriars station and from across the river to the south-southeast. It was also relatively prominent when looking south along the bridge's east footway, intruding on views of the surviving historic piers of the former Blackfriars Railway Bridge (see Figure 2), also designed by Cubitt.

\section{History and construction}

\subsection{History}

Blackfriars Road Bridge is a Grade II-listed structure.
The list description is as follows.

1869, by James Cubitt (?) 5 shallow, segmental arches of cast iron with abutments of grey granite and piers with squat engaged columns, the caps and bases of carved Portland stone. Gothic balustrade of gray granite. (Historic England, 1972)

Although the list particulars suggest some doubt over the original construction, it is generally accepted that it was built to the design of Joseph Cubitt in 1869, comprising five arches.

Figure 3 shows one of a series of images of the history of the bridge now displayed in the pedestrian underpass on the south side of the river.

The Survey of London provides further details on both the current bridge and its predecessor a century earlier.

\section{In 1756 the Mayor, Aldermen and Commons of the City of London obtained authority by Act of Parliament (fn. 243) to build a bridge at Blackfriars, the third bridge across the Thames to be erected in the London area. It was designed by Robert Mylne. (fn. n1) The first pile was driven in 1760; it was made passable as a bridle way in 1768 and was opened to traffic in 1769. It was made free of toll in 1785. Mylne's bridge lasted just over 100 years. Its decay was hastened by the increased scour in the bed of the river following the rebuilding of London Bridge. The present Blackfriars Bridge, which was designed by Joseph Cubitt, was commenced in 1864. (fn. 245). (London City Council, 1950)}

Various works to the bridge have taken place in the last 150 years. Cubitt's bridge, which itself replaced the earlier stone bridge comprising nine arches, remained in good condition, but by the beginning of the twentieth century, the increase in traffic and the 'desirability of laying a tramway on it' (Anderson and Cunningham, 1912: p. 271) suggested that the original width was inadequate. The Corporation of London obtained powers to widen

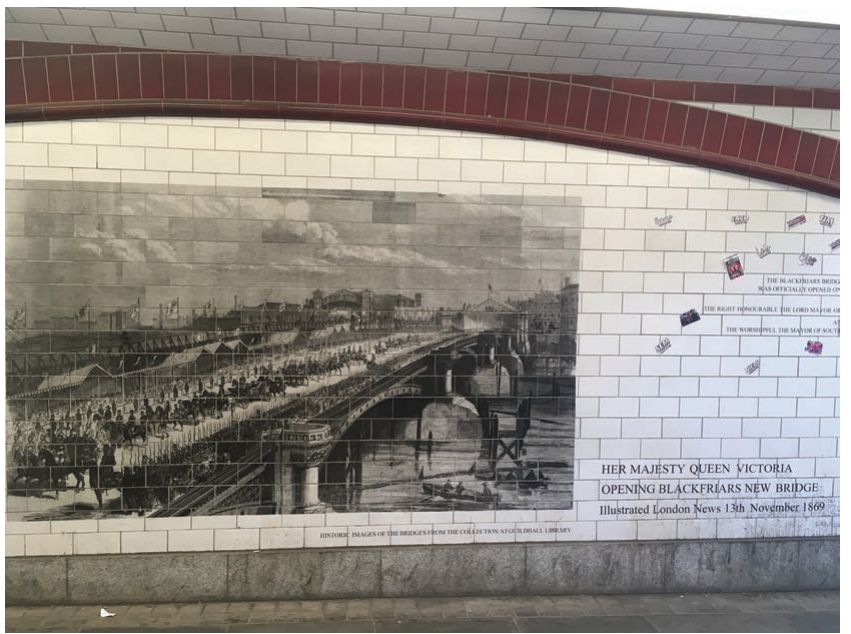

Figure 3. The opening of the bridge by Queen Victoria 
the bridge by 30 feet (ft) $(9 \cdot 14 \mathrm{~m})$, and the works were completed in 1909. Both the original construction and the widening are described in some detail in the paper by Anderson and Cunningham (1912). The widening was effected by 'taking apart and removing the entire west face and re-erecting it $30 \mathrm{ft}$ west of its original position' (Anderson and Cunningham, 1912: p. 273). The gap was infilled using steel ribs with new cross-girders and decking to carry the new roadway. The piers and abutments were extended as required to accommodate the additional width.

In the late 1960s, the Blackfriars Underpass was constructed at the north end of the bridge and the embankment was widened. At this time, towards the northern end of the bridge on its east side, a stone and concrete staircase was built connecting the bridge deck with the embankment below. The staircase was perpendicular to the bridge, and an opening was formed in the parapet to accommodate the top landing, with granite piers set on either side of the opening. It consisted of a short flight of stairs down to a concrete landing, with a further short flight down to the embankment level. The treads, risers and the landing deck were all of concrete. Granite piers were inserted at the ends of the opening in the parapet; these can be seen in Figure 4.

\subsection{Bridge construction}

Each of the five spans has 12 fabricated riveted shallow arched wrought-iron plate girders, sprung from stone piers. The outer girders have embossed medallions (Figure 5). The outer lattice spandrels have floral decoration. Between the arched girders there are lattice braces attached to the web stiffeners. There are lattice spandrels composed of flat and angle sections, above the girders over which the transverse beams that support the bridge deck are laid. There are further ' $\mathrm{T}$ ' section cross-braces between the arched girders. The piers sit on concealed iron caissons sunk into the riverbed and support broad Scottish granite columns with elaborate Portland stone Corinthian columns featuring plants and birds of the

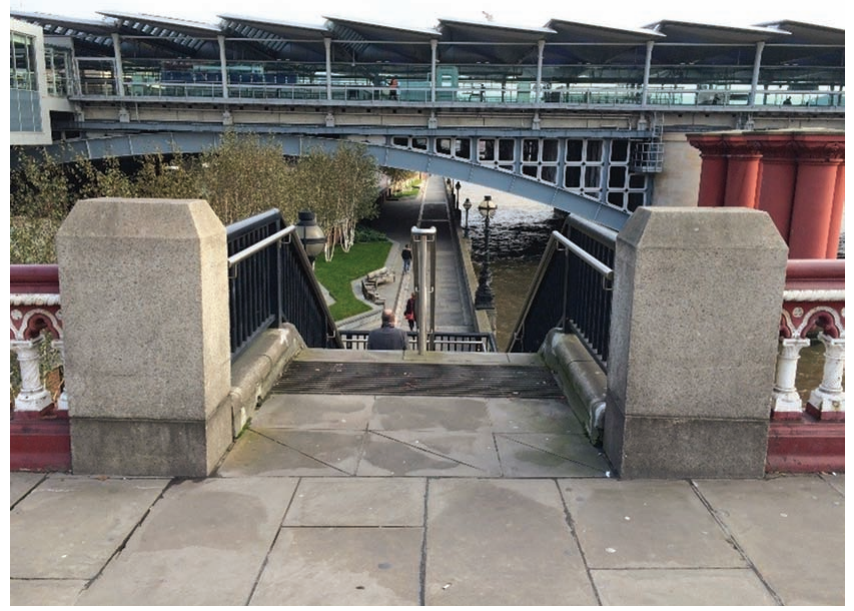

Figure 4. Granite piers at junction between staircase and bridge deck

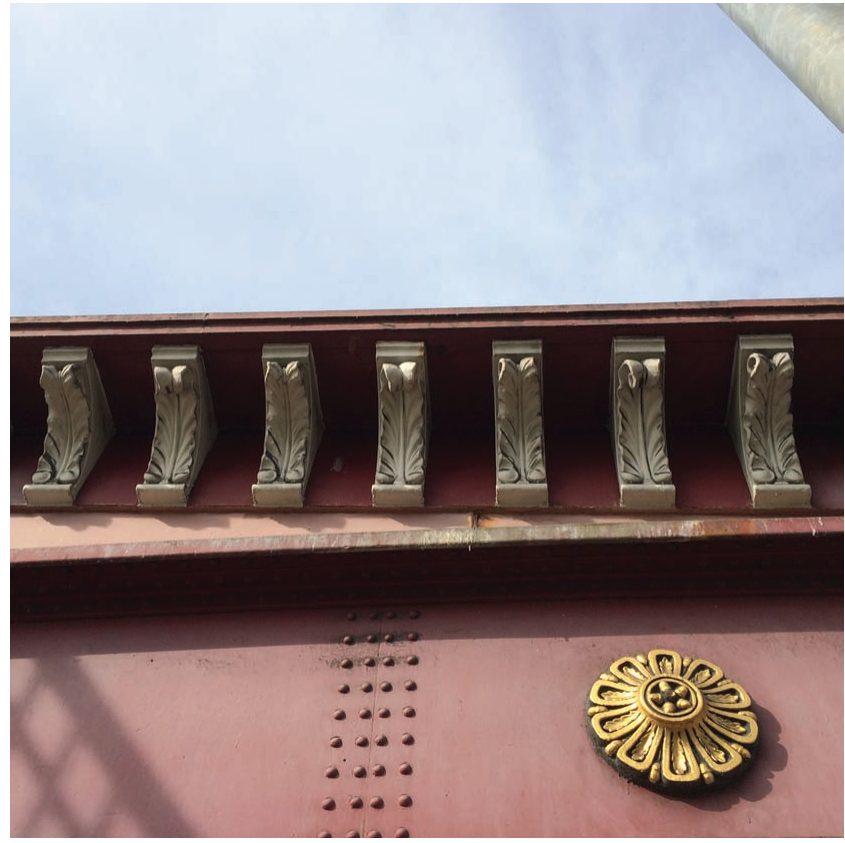

Figure 5. Acanthus decoration on front plate of modillions (note embossed medallions on outer girder of the bridge)

Thames Estuary and River, carved by the sculptor John Birnie Phillip. The columns rise above the parapet level to form granite seating roundels projecting out from the bridge. These form regular breaks to the cast-iron parapet, which takes the form of a miniature gothic colonnade (Thames Tideway Tunnel, 2015).

\subsection{Parapet details}

The bridge parapet is original to Joseph Cubitt's bridge, dating from 1869. It consists of a balustrade above a modillion cornice, made up of separate top rail, balustrade, base and the shelf of the modillion cornice (hereafter referred to as the cornice shelf), supported on cast-iron modillions.

A number of drawings were located from the Corporation of London's archives (Figures 6 and 7). Construction details of the cornice were deduced from these drawings, together with visual observations. The drawings were not entirely consistent with each other but provided sufficient detail for reasonable interpretation, augmented by inspections on-site.

The parapet is elaborately decorated, with the balusters having varied gothic capitals and variously decorated spindles (Figure 8). The arches above the balusters have trefoil heads. Below the balustrade base is a projecting cornice supported on brackets with acanthus leaf decoration (Figure 5). All of these parapet elements are of 6 foot 7 inch $(2 \cdot 1 \mathrm{~m})$ long overlapping castings, with each of its four elements cast separately (top rail, balustrade, base, cornice shelf). The perpend joints between castings do not align vertically with those beneath or above as the castings are staggered in their configuration (Thames Tideway Tunnel, 2015). 


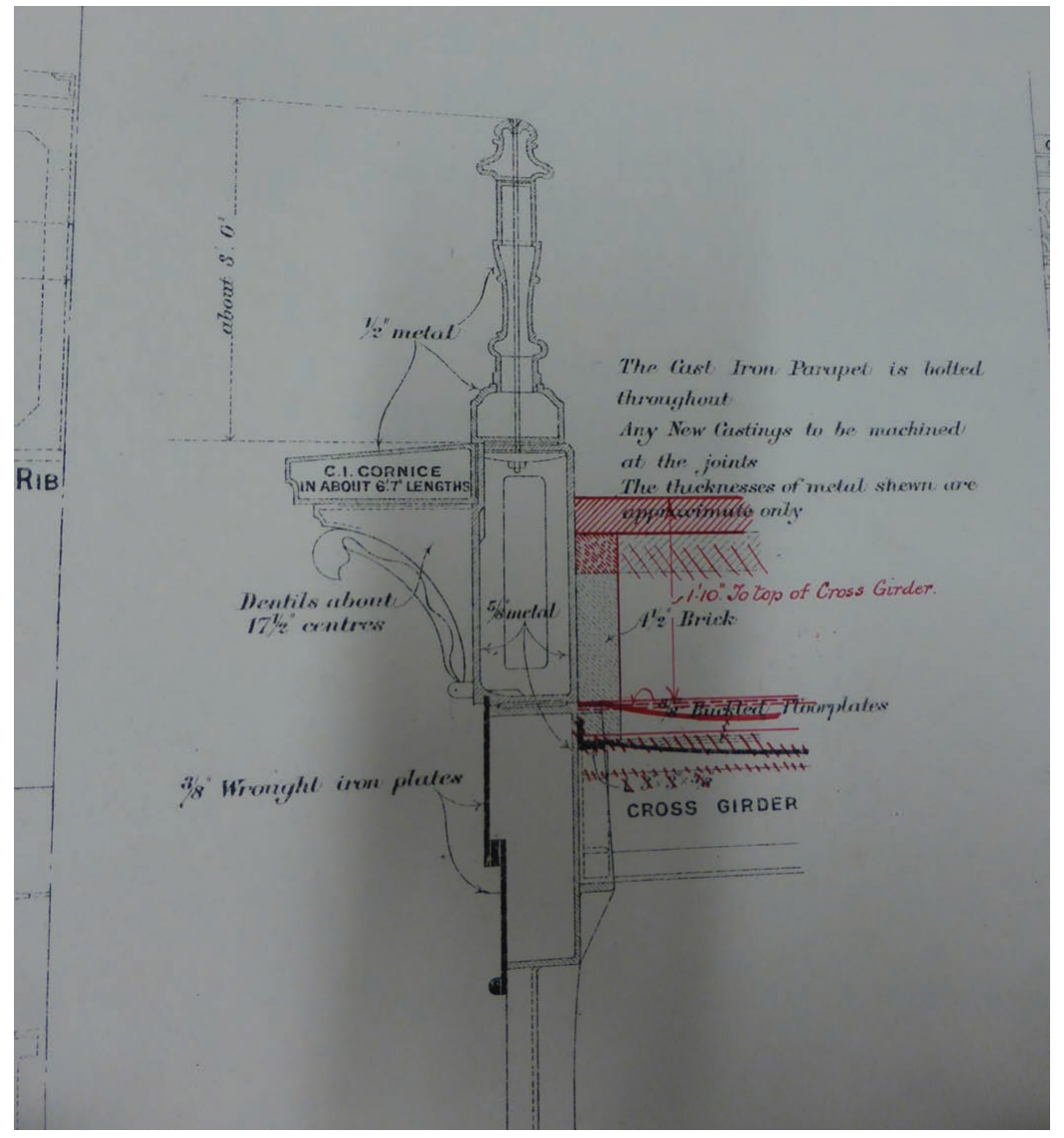

Figure 6. A 1906 section through the parapet (LMA: COL/PL/02/E/006)

The modillions ('brackets') of the cornice are each formed of two castings and are bolted separately into the ironwork of the bridge (Figures 6 and 9). The cornice shelf and brackets appear to be bolted onto a wrought-iron plate which sits over and obscures castings beneath the balustrade base. The joints between these hidden castings were not visible. It was recognised that these details would be among those to be exposed during the course of the works.

In the opening for the 1960s staircase, there was a gap between the staircase and the cut ends of the cornice shelf. The detailing of the shelf at the new opening was considered carefully in the proposals for the works, with chamfered ends specified abutting the staircase, leaving a nominal gap only.

It is noted that the widening carried out in 1909 was on the west side of the bridge and therefore would not have resulted in any alterations to the original parapet in the area of the new staircase on the eastern side. The paper by Anderson and Cunningham (1912) does note that while the original specification for the works envisaged that the west face would be taken apart, the contractors proposed moving each face rib 'as it stood, with its cast-iron spandrels, cornices and hand-rail intact' (Anderson and
Cunningham, 1912: p. 283). This was on the basis that they saw the difficulty of preserving the ornamental cast iron, something which can be well appreciated from a closer view of the parapet. This approach was accepted by the engineer, and in the event was implemented on four of the five arches.

\subsection{Construction}

Prior to applying for consent for the works, it was necessary to confirm all construction details, both existing and proposed, as far as was reasonably possible. While some intrusive investigations were carried out working from the pavement side of the bridge, as described in Section 5, it became apparent that the final details could be confirmed only as the 1960 s staircase was demolished and the initial sections of parapet removed.

Despite extensive searches of archive records, it was not possible to locate details of the connection between the landing and the bridge or the connection of the granite piers to the bridge structure.

At the sides of the staircase opening, two granite piers, each comprising a base and an upper section, were located at the back of the pavement. It could be seen that the upper and lower 


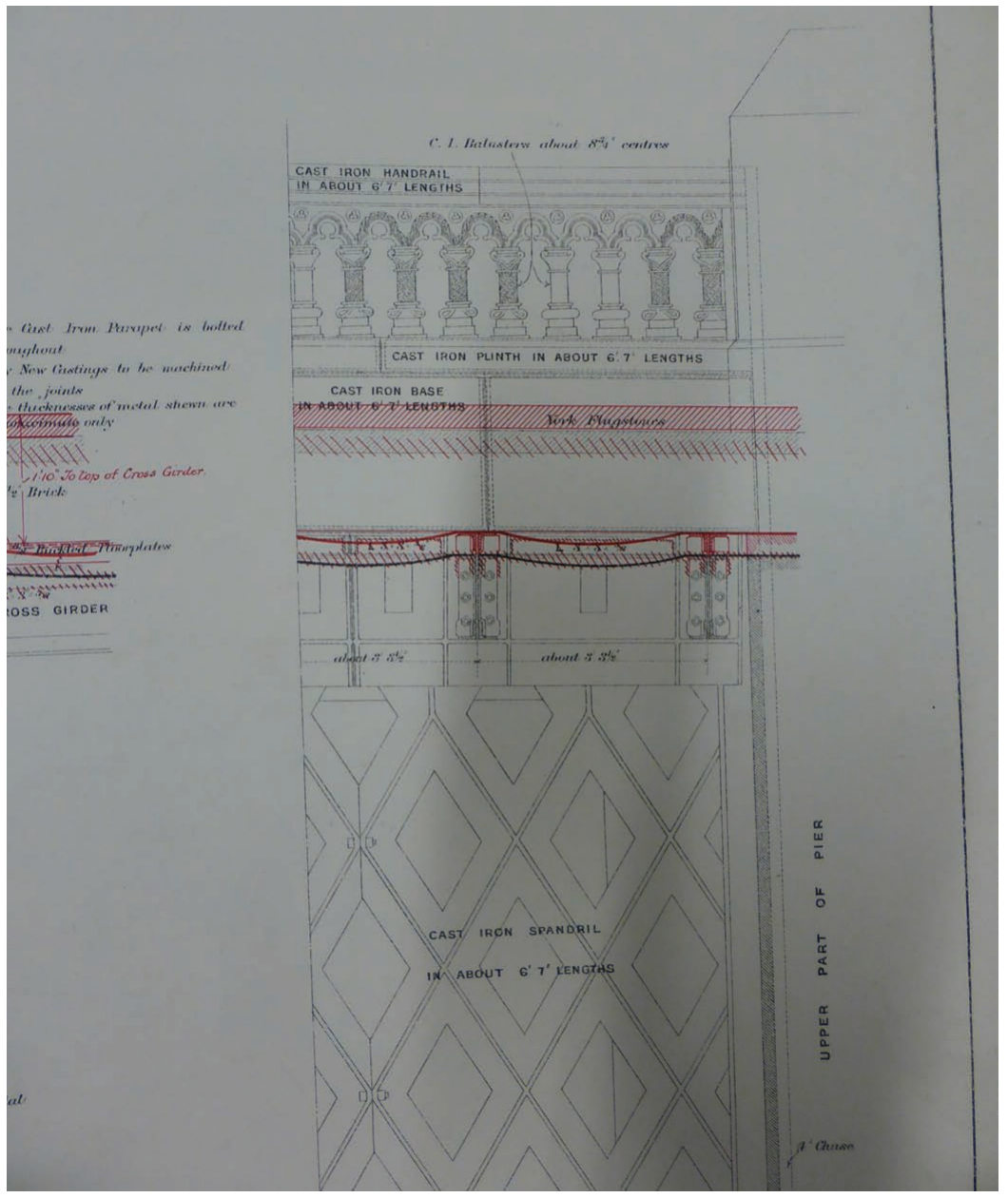

Figure 7. Drawings of the parapet from the Corporation of London's archives

sections of the parapet at either side were recessed into the piers with a mastic joint surround (seen in Figure 10). Probing established that the embedment within the piers was approximately $50 \mathrm{~mm}$. Details of any mechanical fixings between the upper and lower sections of the piers and their seating on the bridge could not be established.

It was observed that while the baluster spindles (see Section 3.3) appear on first sight to have a regular alternating pattern, on closer inspection there is more variation in the decoration and the extent of repetition is quite limited. This had implications on the works programme where new castings were required due to the need for more individual moulds than had been initially estimated.

\section{Consented scheme}

\subsection{Principal scope}

The removal of the $1960 \mathrm{~s}$ staircase and installation of its replacement in a slightly different location required the removal of part of the parapet and reinstatement of a length to close the previous access. The granite piers on either side of the original opening were to be removed and, subject to verifying that they could be lifted and reinstated without significant damage, reinstated at the new opening location.

The extent of cast-iron elements to be removed/replaced was assessed very carefully on-site to minimise the intervention. This required detailed review of joint locations so that precise positions could be identified on the drawings. It was noted earlier that the joints between castings are not aligned vertically, and this was also taken into account.

An extract from one of the drawings submitted for listed building consent is included as Figure 11(a). Some details were revised subsequently following deconstruction of parapet elements.

The removal of the 1960s stair and its replacement are not the focus of this paper, but these are included here in the context of the impact that these activities had on the works to the parapet. 
Nineteenth-century cast-iron parapet of Blackfriars Road Bridge, London, UK

Lazarus

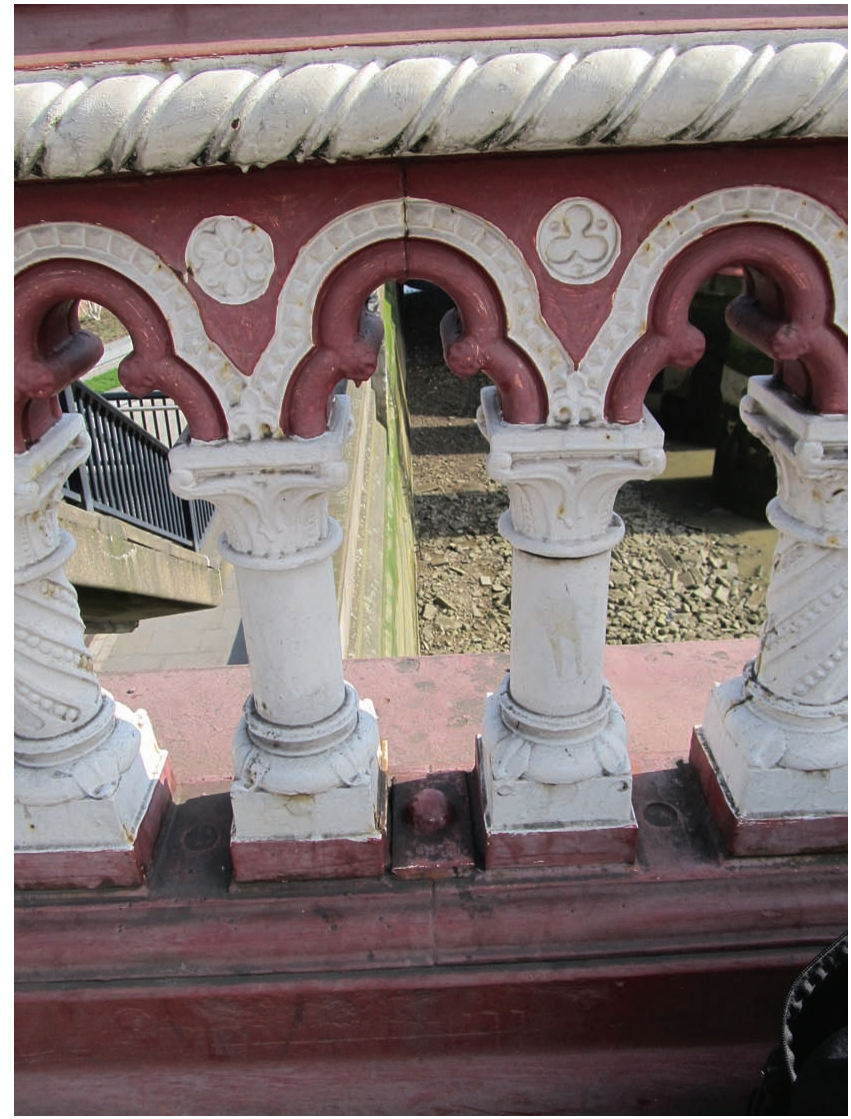

Figure 8. Detail of parapet balusters

The detail of the connection between the new landing and the cast-iron beam at the location of the opening, and in particular the provision of allowance for thermal movement, was the principal issue here. A tapered granite 'shelf' was used below the landing for aesthetic reasons, with bearings installed on the shelf to support the new landing. These allowed the landing to extend longitudinally with thermal expansion/contraction and were preloaded to allow for 'breathing' of the arches of Blackfriars Road Bridge. The stone was sourced to match the older Cornish granite used on the bridge, and testing was carried out to verify the necessary performance.

\section{Investigations}

\subsection{General}

In order to provide comprehensive details for listed building consent, it was recognised that some investigations would be necessary. Equally, it was known that these would necessarily have some limitations - for example, details such as the connections between cast-iron sections, both longitudinally within the parapet and between elements such as the brackets and shelf. would be confirmed only once the works were in progress (see Figure 9). The limitations were due in part to the extent of intervention required, which would itself require separate application with full details, and in part to access restrictions before the main works started. While some works could be carried out from the footway, others required full scaffolding to enable safe access for work to be carried out above the river. Similarly, the necessary licences to erect scaffolding on the river side of the bridge were not obtained until the scheme had consent.

\subsection{Scope of investigations}

It was determined that investigations would be carried out from the footway to identify as far as could be seen the following information

- the connection between the granite piers and the bridge structure below

any mechanical connection between the granite piers and the staircase

- the make-up of the iron sections to confirm/extend information from the drawings located in archives

- the connection between the staircase and the bridge

- the connection between the cast-iron sections which make up the parapet and the granite piers.

The findings from the investigations are described in the relevant sections that follow and are included in the detailed heritage method statement prepared by the contractor VolkerStevin (2015) as required for listed building consent discharge of condition.

\section{The works}

\subsection{General}

Agreement was reached with the City of London that works could start on the basis of the findings of the investigations, appropriate revisions to the set of drawings prepared for the initial heritage consent and a detailed method statement. A set of 'hold' points was identified where further interim agreement would be needed based on inspection of the construction details revealed as parapet deconstruction proceeded.

The works were carried out from the footway and also from the staging erected over the river and accessed from the worksite on the embankment to the east of the bridge.

The first stage comprised the removal of the 1960s staircase and the granite piers. The precast landing was saw-cut prior to removal of the flights. The upper sections of the granite piers were carefully removed initially followed by the larger, lower sections. This enabled confirmation of the mechanical fixings (or lack of them) for review in relation to the subsequent relocation. The sections were then carefully wrapped and labelled and taken into store in a compound behind the embankment.

\subsection{Granite piers}

It had been assumed that there would be some mechanical fixing between the upper and lower sections of the granite piers. While this was felt to be a reasonable assumption, it transpired that no 


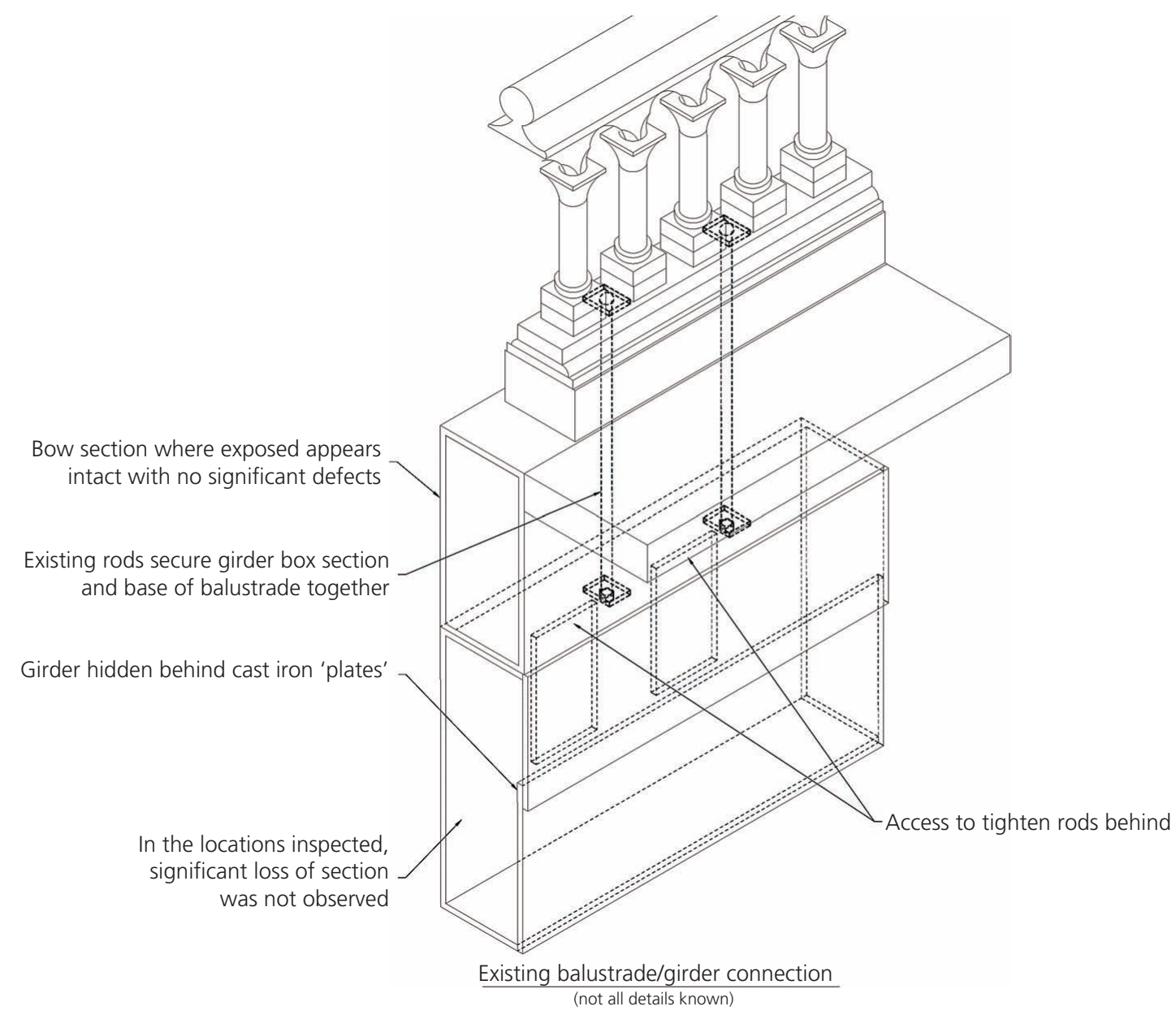

Figure 9. Connection detail between the parapet and the edge girder of Blackfriars Bridge (extract from Thames Tideway drawing)

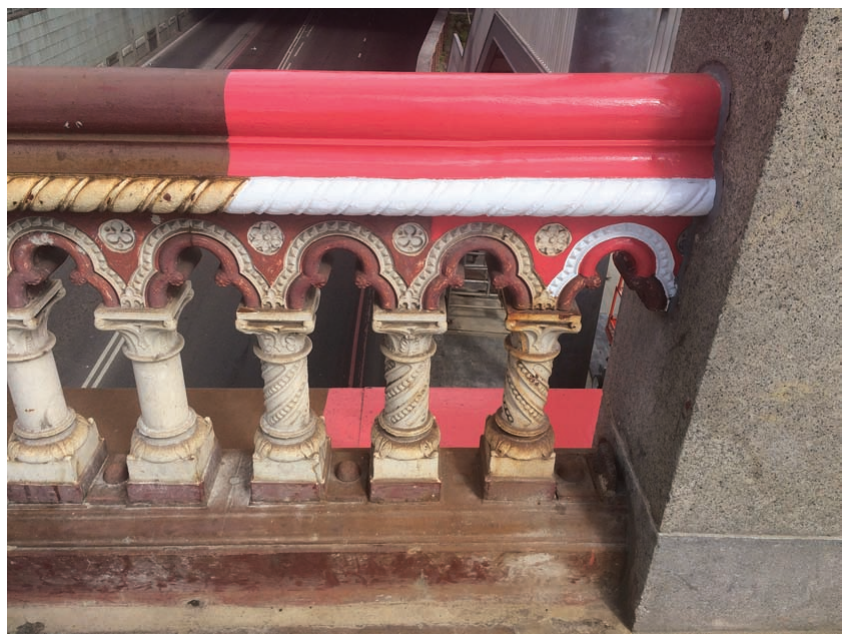

Figure 10. Contrast in paint colour between original (weathered) and new sections such connection existed and reliance had been placed on gravity loads. A risk assessment was carried out to determine whether the piers should be reinstated on a like-for-like basis, without additional intervention into the fabric, or whether a form of fixing should be introduced and on what basis this should be designed. This is discussed in more detail in Section 8.

\subsection{Cast-iron balusters}

Visual inspection had identified the presence of rust and cracking in the baluster spindles and bases. It was agreed that a number of these, specifically identified, would be repaired, and others were identified as needing to be replaced due to the extent of defects. As the works progressed, it became evident that the damage was more widespread than had been recognised initially (Figure 12), largely due to the impact of both water ingress inside the sections and substandard maintenance. For example, joints in the bases which had appeared to have been repaired and repainted were found to contain a filler product with limited integrity. It was apparent that repairs and replacement would be more extensive than originally envisaged. A number of the balusters cracked on 

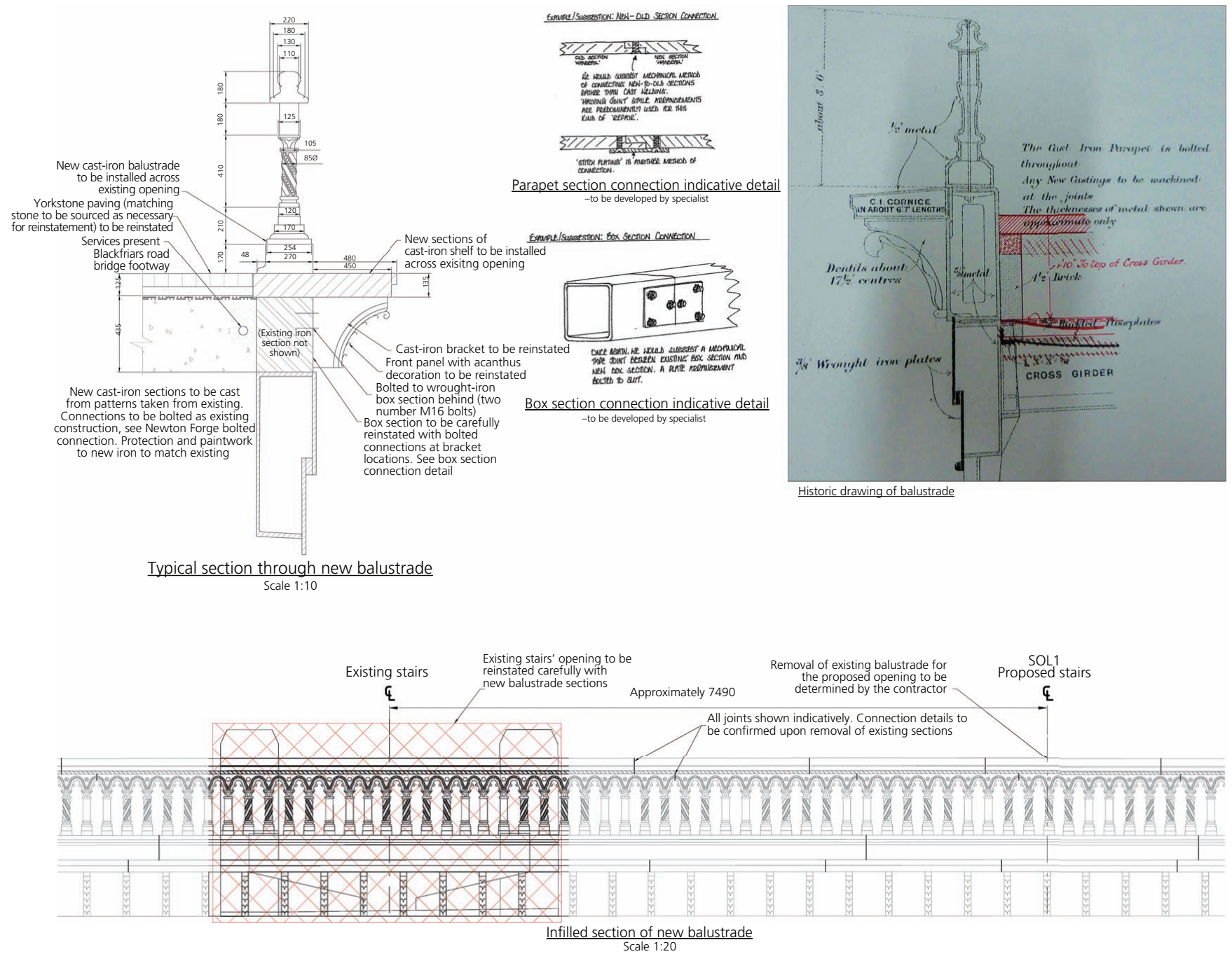

(a)

Figure 11. (a) Extract from drawing showing extent of works and indicative fixing details (dimensions for new works given in mm); (b) extract from drawing showing proposed fixing details (continued on next page)

removal even with careful handling, increasing the extent of repair and replacement needed.

\subsection{Parapet top rail and base}

Removal of the end sections of handrail at the granite piers revealed that these had been filled with a cementitious material. It is not known at what stage this was done nor whether it was done to stiffen the section or to prevent water ingress. No records have been found which would provide some clarity on this. It was also found subsequently that a similar material had been used as filling within the base sections. This is shown in Figure 13.

The consequence of this was that the minimum intervention approach of disassembly as had been proposed initially was not feasible. The sections had to be cut out on-site and the concrete then drilled out. It was agreed that the replacement elements would also be filled, using a concrete mix specified from tests carried out on the existing infill.

\subsection{Cast-iron shelf and brackets}

The overhanging shelf and supports were badly corroded in several locations. This resulted in several sections cracking on removal. In addition, in many cases, the acanthus decorative fronts were damaged and had to be recast.

\subsection{Setting out}

Setting out the works to match the pavement levels and falls while providing the necessary seating for the new landing proved to be complex. Further complications resulted from the location of the service pipes and filler material behind the base of the balustrade; it was thought likely that this had moved during the removal of the original parapet sections. This caused difficulties 


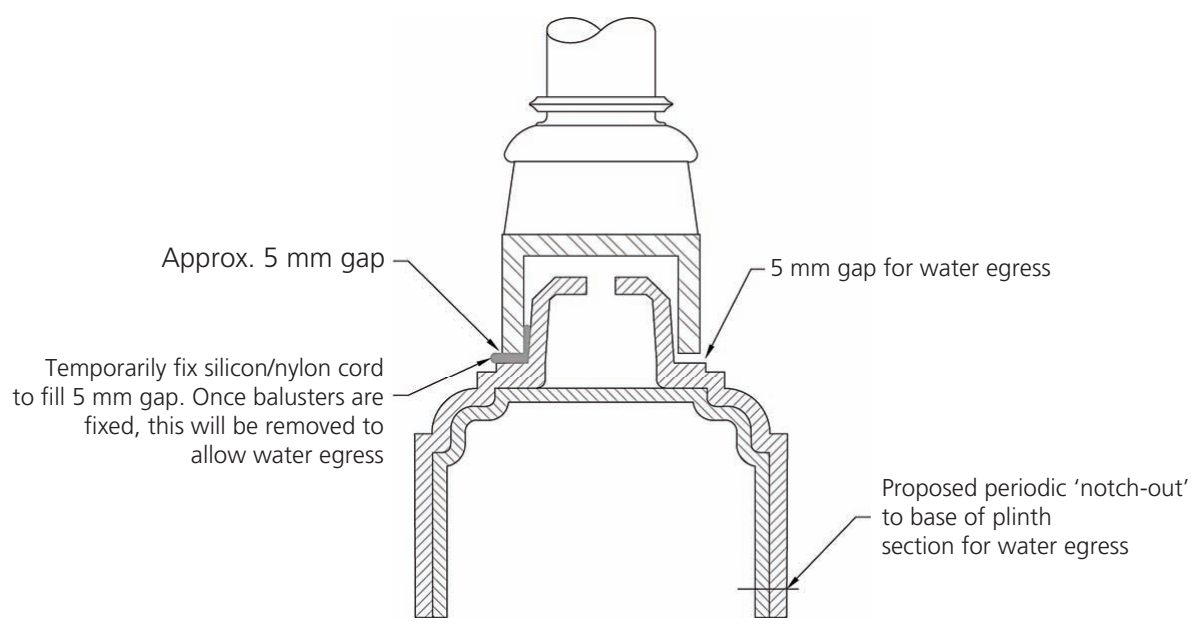

12. Proposed water egress points for cast-iron balustrading

(b)

Figure 11. Continued

in locating the granite base in the recess which had been formed to receive it.

The piers and the handrail were not perfectly aligned; even with relocation of the services behind, this resulted in a sizeable gap where the balustrade met the pier. The mastic joint formed was overly large and highly visible in consequence; it was later concealed by a cover plate (similar to those found elsewhere on the bridge).

\section{New castings}

The specialist iron work was undertaken by Newton Forge, a firm experienced in the conservation and restoration of traditional cast

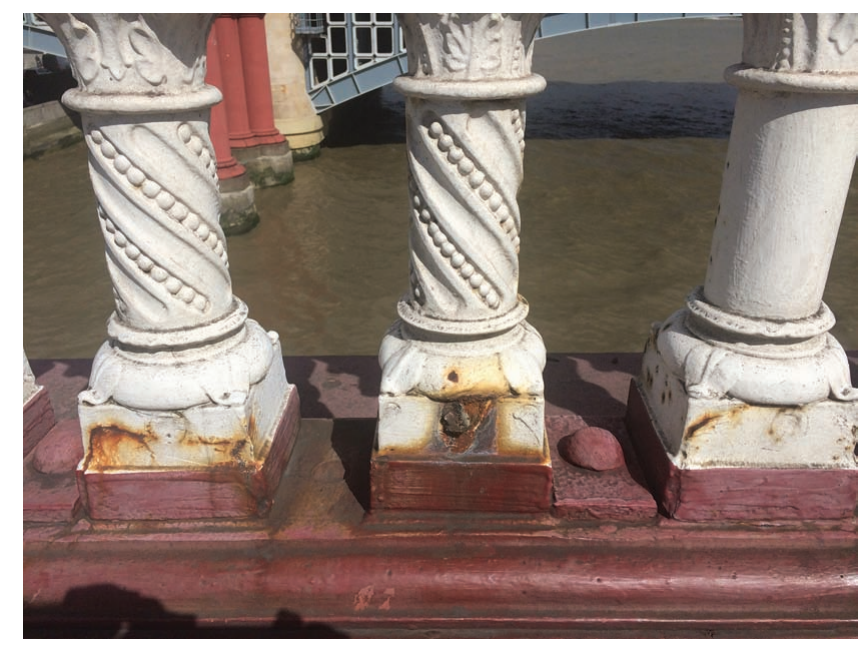

Figure 12. Evidence of corrosion on the parapet, most apparent on the baluster bases iron together with the casting of new material where required. They have a traditional forge and tools together with modern equipment and the capability to both repair and, where required, recreate small decorative details such as those incorporated within the bridge parapet. New castings were required to match the existing, with a ductile iron used. Mechanical connections were used throughout - that is, bolts and plates (indicative details are included in Figure 11).

Once the relevant sections had been deconstructed and removed to Newton Forge's works and some of the new castings had been made, a visit was arranged for representatives from the client, the City of London and Arup. This allowed a detailed view of the

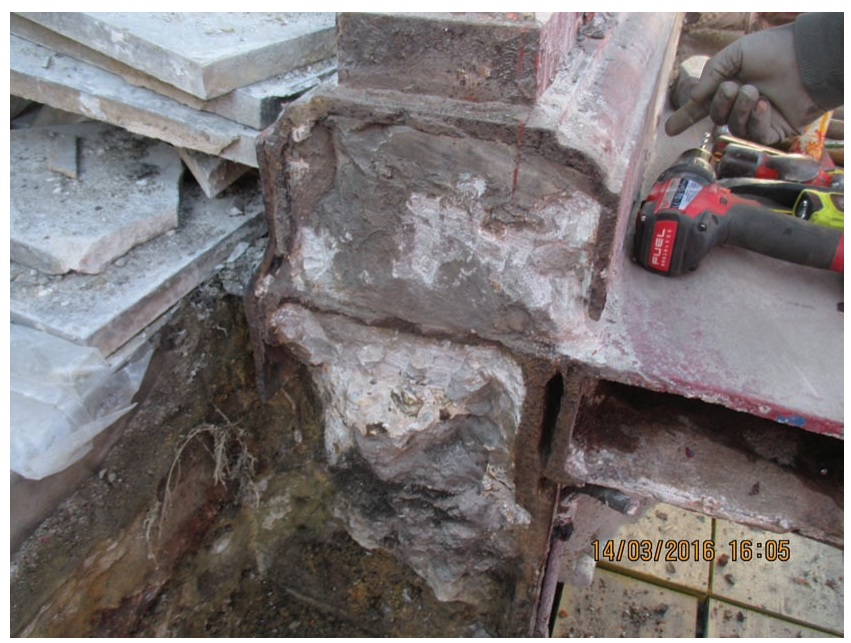

Figure 13. Removal of the parapet base showing the concretefilled sections 
condition of the original cast iron and discussion of the findings, together with sight of the new castings.

It was agreed that, subject to the consent of Historic England, the work would proceed on the basis of the following.

Where the existing wrought-iron fixings had corroded, they would be replaced with galvanised steel, which has greater durability. This also removed the potential need to determine the strength of the wrought iron and to identify its source.

- The condition of the square base to the balustrade 'spindle' was badly corroded in a number of cases, with some sections missing entirely. For the 21 bases where this was the case, Newton Forge proposed to recast only this lower section as the remaining section of the spindles were felt to be in sufficiently good condition; this enabled more of the original spindles to be retained with only minor alterations. This also resulted in an additional 4 weeks for the castings rather than the minimum of 8 weeks which would be needed to recast the entire section including the spindles.

- The new sections of box beam and base plinth cast to infill the opening for the 1960s stair would be filled with a cementitious material corresponding to a conventional design mix concrete. While this would not replicate the material originally used for filling the sections, it was recognised that it was most unlikely that the original mix could be matched in terms of sourcing the same materials; use of a standard mix also provided a record of source and quality.

The specification for paintwork for both the new and reinstated metalwork was in line with the Highways Agency's specification series 1900: Protection of steelwork against corrosion (HA, 2014). While photographs exist showing the finishing coat for the parapet as being of various colours during its lifetime, the new sections were painted using the same colour used for the most recent recoating (undertaken by the City of London). It is intended that the whole length of the bridge is to be repainted in the short term, but at this stage the contrast between old and new is particularly striking (Figure 10).

\section{Condition of the parapet and design loads}

\subsection{Parapet in the area of the works}

Blackfriars Road Bridge was constructed in 1869. At that time, the traffic using the bridge would have been significantly different from that using it today, and the risks from impact loading would not have been assessed in accordance with current methods.

Visual inspection showed that a number of the balusters had suffered significant corrosion, with this also affecting areas of the base. Cracking was also apparent. Some of these defects are clearly visible in Figure 12.

It was agreed at the outset with the City of London that the parapet would be reinstated on a 'like-for-like' basis. This acknowledged that there was no requirement either to design new elements or to strengthen the existing sections to meet current highway loading requirements. A further issue arose when it was found that the granite pier sections were not mechanically connected and that the base fixings were fairly nominal and of limited capacity in relation to application of horizontal loads. In their original location, the piers were partially contained by the concrete staircase structure, but alternative approaches were considered for the relocation of the piers at their new location where the new lightweight landing would offer no such protection. The risk issues associated with these were considered explicitly and documented, together with mitigation considerations such as the installation of protective bollards which would be visually intrusive. It was noted in the risk assessment that the footway had been widened and that the probability of vehicle impact was therefore lessened.

Subsequent to completion of the works, terrorist incidents occurred on two of London's bridges over the Thames: at Westminster Bridge on 22 March 2017 and on London Bridge on 3 June 2017. In both cases, vehicles (a car in the first attack and a van in the second) were driven directly at pedestrians on the bridges. The use of vehicles as 'weapons' appears to be a relatively recent development, with lorries also used in attacks in Continental Europe. At the present time, it is not believed that design loads have been changed in response to this, but much more extensive use of protective bollards at a number of sites identified as vulnerable within the capital has been introduced.

It was also recognised by the City of London that the works associated with the new lift and staircase affected only a small proportion of the overall length of parapet along the east and west sides of the bridge. Given the condition of the parapet identified in the area of the works, it was regarded as highly likely that similar issues would exist elsewhere, and load testing of the parapet was therefore commissioned by the corporation.

\subsection{Bridge parapet testing}

The load testing was specified by Aecom. A section of parapet which was in poor condition on the southbound was selected, and a further section on the northbound side which connected to a granite pier was also tested.

Applied loads were specified in accordance with BS EN 13176:2012 (BSI, 2012). It was acknowledged that the parapets would not be likely to withstand vehicle impact loads, but it was also considered that both the width of the footways and the straight alignment of the bridge would mitigate against vehicular incident. Accordingly, the parapet was tested under static horizontal loads (vertical loading was also not considered to be critical) to verify pedestrian safety.

The applied horizontal loadings comprised a uniformly distributed load applied to the top of the handrail and a concentrated load applied to the middle point of the balusters. These were not applied simultaneously. Structural safety was verified as ultimate 
limit state, while the serviceability of the parapet was verified as serviceability limit state. Loads were applied in a series of stages and deflections were measured.

The loads were applied using a series of rigs and flat jacks as shown in Figure 14. Acceptance criteria were specified in terms of deflection limits and also visible indications such as cracking, local bucking or distortion. The parapets performed better than what might have been anticipated, with only very limited deflections recorded and no visible indications of distress. As has been shown with other such tests, unanticipated reserves of strength in bridge parapets may be demonstrated in some cases.

\section{Other bridges}

It is of interest to note that at a similar time, works have been undertaken to the parapets of the Albert Bridge in Glasgow (Engineers R. Bell and D. Miller of Glasgow, constructed 1871) and to Westminster Bridge in London (by Thomas Page and Sir Charles Barry, 1854-1862). Both involved the replacement of the original decorative parapets with elements which matched the originals as closely as possible. The specialist ironwork in both cases was undertaken by Ballantine Castings Ltd.

\subsection{Albert Bridge, Glasgow}

The present Albert Bridge is the fifth on or close to the site and is Grade A listed. It has concrete piers and abutments filled with cast-iron caissons, with foundations approximately $86 \mathrm{ft}(26 \cdot 2 \mathrm{~m})$ below water level. It has three curved arch spans and is $410 \mathrm{ft}$ (125 m) long and $60 \mathrm{ft}(18 \cdot 2 \mathrm{~m})$ wide.

It has eight arched wrought-iron riveted girders. The piers are $11 \mathrm{ft}(3.35 \mathrm{~m})$ wide and are faced on the outside with Scottish granite. The arch ribs are masked by cast-iron spandrels, filled in with panels of scrollwork and armorial shields including the

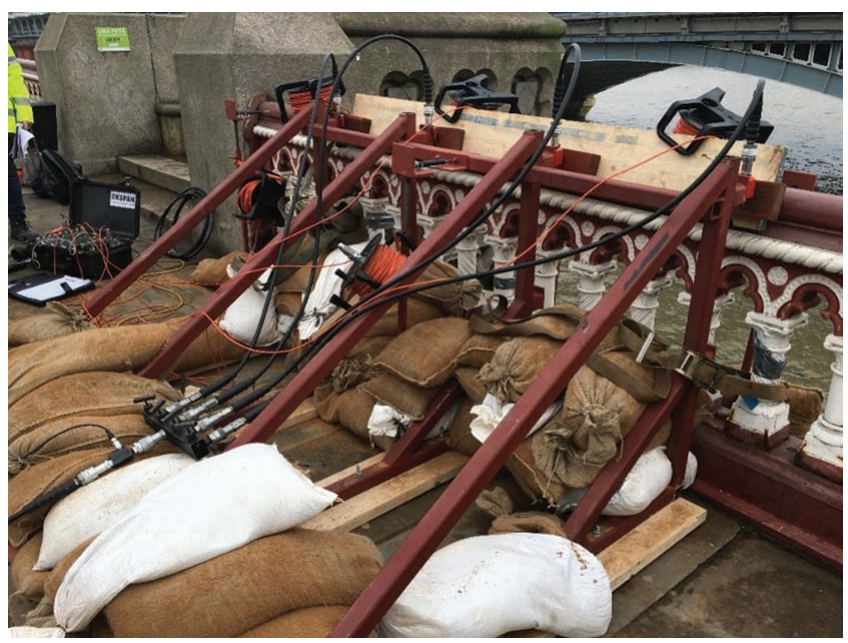

Figure 14. Static testing of parapet: loads applied to handrail (City of London Corporation) royal coat of arms and those of various local trades. A cast-iron cornice is fixed to the main edge girder and surmounted by a massive ductile iron parapet, with panels at the centre of the bridge bearing the ancient arms of the City of Glasgow (Glasgow City Council, 2016).

The original ornate cast-iron parapets were identified as being in very poor condition with parts missing and others cracked to an extent, which made repair impractical. Conservation and restoration work on the bridge included their replacement with identical but stronger ones. Each new $1800 \mathrm{~mm}$ parapet section comprised five sections which had to be joined mechanically prior to erection on the wrought-iron substructure.

\subsection{Westminster Bridge}

Westminster Bridge is a seven-span structure $250 \mathrm{~m}$ long across the River Thames close to the Houses of Parliament. It was constructed in 1862 of cast and wrought iron, with piers and abutments of grey granite and is Grade II* listed. Each span comprises cast-iron arched ribs between 29 and $37 \mathrm{~m}$ long. The City of Westminster decided to undertake a full refurbishment of the bridge, including an assessment of its load-carrying capacity following the principal inspection carried out in 1989. The assessment and load testing are described in the paper by Yeoell et al. (1993). While this focuses primarily on the deck capacity, feasibility of strengthening and proposals for this work, it also notes that the 'elegant cast iron parapets provide inadequate containment for vehicle or crowd loading. The decision was taken in this case to replace them with ductile iron parapets of similar appearance in order to retain what was described as a 'dominant feature of the bridge' (Yeoell et al., 1993: p. 314). In addition to commentary on the load testing and its results in comparison with the calculated capacity, the paper identifies the potential for investigations, assessment and upgrade works which may be relatively costly and time-consuming but can allow the retention and continued use of a major heritage structure.

\section{Conclusions}

Works to the historic cast-iron parapet on the east side of Blackfriars Bridge to replace the 1960s stair to the riverside park below with improved, modern access including a lift were carried out successfully from 2016 to 2017 (Figure 15). The scope of the works was relatively small, but the complexity arising from the provision of safe access, the need to understand full details of construction in order to obtain the necessary consents and the objective of minimising loss of heritage fabric was perhaps disproportionate.

The success of the project relied on close co-operation between all parties. It highlighted both the value of archive information and the need to be alert to differences from such information encountered on-site, a feature of works to existing structures more generally. It has enabled the retention of some highly decorative nineteenthcentury cast iron and demonstrated the contribution of traditional crafts in manufacturing replacement elements where needed. 
Nineteenth-century cast-iron parapet of Blackfriars Road Bridge, London, UK

Lazarus

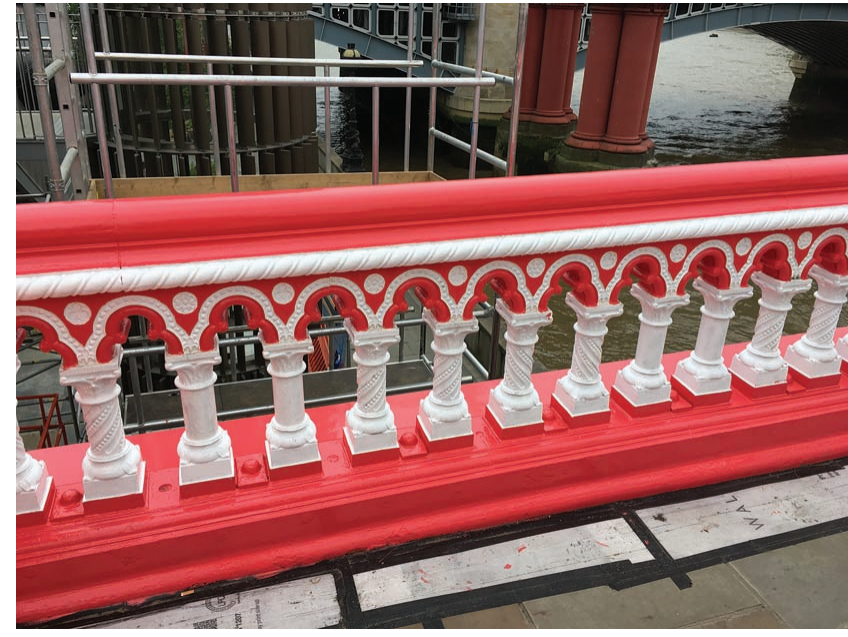

Figure 15. Blackfriars Road Bridge: a completed section of castiron parapet

The role of physical load testing in situ has been demonstrated in determining the capacity of such structures. The project has also demonstrated the competing requirements of retaining heritage structures as far as practicable while fully addressing the risks from the various loads which may be anticipated in the twentyfirst century. Even while this paper was in preparation, the risk of intentional vehicular impact loading has become an issue requiring urgent attention and mitigation.

\section{Acknowledgements}

The author wishes to thank colleagues at Arup and in particular Chris Millar for his work on the project and contribution to the paper, together with Paul Monaghan, assistant director engineering, City of London. Thames Tideway has kindly agreed to the publication of this paper.

\section{REFERENCES}

Anderson D and Cunningham K (1912) The widening of Blackfriars Bridge. Minutes of the Proceedings of the Institution of Civil Engineers 190(1912): 271-292, https://doi.org/10.1680/imotp.1912.16870.

BSI (2012) BS EN 1317-6:2012: Road restraint systems. Pedestrian restraint system. Pedestrian parapets. BSI, London, UK.

Glasgow City Council (2016) News Archive. Glasgow City Council, Glasgow, UK. See https:/www.glasgow.gov.uk/index.aspx? articleid=20218 (accessed 02/07/2018).

HA (Highways Agency) (2014) Manual of Contract Documents for Highway Works: Volume 1 - Specification for Highway Works. HA, London, UK.

Historic England (1972) National Heritage List for England, Blackfriars Bridge, List Entry Number 1064717. Historic England, London, UK. See http://www.historicengand.org.uk/listing/the-list/list-entry/1064717 (accessed 24/09/2018).

London City Council (1950) Blackfriars Bridge and Blackfriars Road. In Survey of London: Volume 22, Bankside (The Parishes of St. Saviour and Christchurch Southwark) (Roberts H and Godfrey WH (eds)). London County Council, London, UK, pp. 115-121. See http://www. british-history.ac.uk/survey-london/vol22/pp115-121\#fnn245 (accessed 15/09/2018).

Thames Tideway Tunnel (2015) Thames Tideway Tunnel Heritage Statement: Application for Planning Permission and Listed Building Consent for the Provision of New Stairs and Lift to the North East of Blackfriars Bridge. Thames Water Utilities Ltd, Reading, UK, 100RG-PNC-LCORP-000004 AB, 11. See http://www.planning2. cityoflondon.gov.uk/online-applications/files/DFCB2C89176644C1AD 9ADA766A95F124/pdf/15 00589 FULL-HERITAGE STATEMENT297506.pdf (accessed 02/07/2018).

VolkerStevin (2015) Blackfriars Millennium Pier Reconstruction and Marine Vessel Relocations Listed Building Consent Discharge of Condition Heritage Method Statement. VolkerStevin, Preston, UK, Listed Building Consent 15/00590/LBC.

Yeoell D, Blakelock R and Munson SR (1993) The assessment, load-testing and strengthening of Westminster Bridge. In Bridge Management 2: Inspection, Maintenance, Assessment and Repair (Harding JE, Parke GAR and Ryall MJ (eds)). ICE Publishing, London, UK, pp. 307-315.

\section{How can you contribute?}

To discuss this paper, please email up to 500 words to the editor at journals@ice.org.uk. Your contribution will be forwarded to the author(s) for a reply and, if considered appropriate by the editorial board, it will be published as discussion in a future issue of the journal.

Proceedings journals rely entirely on contributions from the civil engineering profession (and allied disciplines). Information about how to submit your paper online is available at www.icevirtuallibrary.com/page/authors, where you will also find detailed author guidelines. 